\title{
When women attack
}

\section{Sex scandals, gender stereotypes, and candidate evaluations}

\author{
Bryan McLaughlin, Texas Tech University \\ Catasha Davis, University of Wisconsin-Madison \\ David Coppini, University of Wisconsin-Madison \\ Young Mie Kim, University of Wisconsin-Madison \\ Sandra Knisely, University of Wisconsin-Madison \\ Douglas McLeod, University of Wisconsin-Madison
}

\begin{abstract}
AвSTRACT. The common assumption that female candidates on the campaign trail should not go on the attack, because such tactics contradict gender stereotypes, has not received consistent support. We argue that in some circumstances gender stereotypes will favor female politicians going negative. To test this proposition, this study examines how gender cues affect voter reactions to negative ads in the context of a political sex scandal, a context that should prime gender stereotypes that favor females. Using an online experiment involving a national sample of U.S. adults $(N=599)$, we manipulate the gender and partisan affiliation of a politician who attacks a male opponent caught in a sex scandal involving sexually suggestive texting to a female intern. Results show that in the context of a sex scandal, a female candidate going on the attack is evaluated more positively than a male. Moreover, while female participants viewed the female sponsor more favorably, sponsor gender had no effect on male participants. Partisanship also influenced candidate evaluations: the Democratic female candidate was evaluated more favorably than her Republican female counterpart.
\end{abstract}

Key words: Gender cues, gender stereotypes, political attack ads, sex scandals, partisanship, candidate evaluations

$\mathrm{G}$ ender is often a salient factor when a woman runs for political office in America. ${ }^{1,2}$ Yet, the conventional wisdom that female politicians face an inherent disadvantage due to gender stereotypes has not received consistent support. ${ }^{3,4,5}$ This inconsistency is particularly well illustrated in the negative advertising literature. The common assumption has been that female politicians should not go on the attack because such tactics would activate negative stereotypes. ${ }^{6,7,8}$ Several studies have found, however, that women actually stand to gain by employing negative campaign messages against male candidates. ${ }^{9,10,11}$ Recent work has clarified some of the conditions under

\section{doi: $10.1017 /$ pls.2015.1}

Correspondence: Bryan McLaughlin, Department of Advertising, College of Media and Communication, Texas Tech University, 3003 15th Street Lubbock, TX 79409. Email: bryan.mclaughlin@ttu.edu which gender stereotypes are likely to be a disadvantage for an attacking female politician. ${ }^{12}$ This study extends this work by arguing that there are certain circumstances in which gender stereotypes will favor females going on the attack.

Although negative political advertisements have become a fixture in political elections, ${ }^{13}$ there is no consensus regarding the effectiveness of negative advertising. While some studies suggest that employing negative ads can be a risky proposition, ${ }^{14}$ going on the attack does often achieve the desired effect of eroding support for an opposing candidate. ${ }^{15,16}$ But, many citizens have little tolerance for negativity in politics, and attack ads can frequently result in negative evaluations of, and feelings toward, the sponsor of the ad. ${ }^{17,18}$ The negative consequences of going on the attack are typically referred to as "backlash" effects. ${ }^{19}$ 


\section{When women attack}

The degree to which candidates face a backlash for going on the attack (if they do at all) depends upon who is sponsoring the ad. In particular, voters are influenced by whether they believe the source of a negative ad is credible and trustworthy. The extant literature has largely assumed that gender acts as a source cue that activates gender stereotypes, which invariably undermine a female politician's ability to act "masculine" and go on the attack. We argue that there are circumstances in which gender stereotypes should favor female politicians going negative. Stereotypes are complex, multifaceted mental networks, and different associations can be brought to the top of the mental bin at different times. ${ }^{20}$ When specific networks are activated, the associations they make salient will be used for evaluating incoming information. Attack ads are not always evaluated in a binary fashion for whether they conform to or counter gender stereotypes. Instead, we expect a more nuanced dynamic to play out when viewers are exposed to stereotypical information-namely, that the specific stereotype association activated (e.g., females are compassionate versus females are passive) will influence how gender is used to evaluate the target of a negative attack.

This study examines how gender cues affect voter reactions to negative ads in the context of a political sex scandal. Consistent with the evolutionary psychology literature, we posit that a political sex scandal with a male culprit should activate mental assumptions about males being deceptive and unfaithful and females being nurturing, honest, and committed. ${ }^{21}$ These mental associations should then be used as the basis for evaluating incoming political information, not just for assessing whether going on the attack is masculine, thus allowing females to be seen as justified in going negative. Additionally, drawing upon prior research, we expect that other important factors will moderate the effects of female-sponsored attack ads, namely, candidate political affiliation ${ }^{22}$ and voter gender. ${ }^{23}$

In order to test these expectations, we employ an online experiment with an originally produced television news story about a fictitious congressional candidate from Colorado who is under fire for sending inappropriate texts to a young female intern. The attack ads were operationalized as a political e-mail from the candidate's opponent (either a male or female, depending on the condition), attacking the scandalized candidate as being unfit for office. By manipulating the attacking politician's gender and party affiliation, the design of this study allows us to clarify some of the conditions under which female politicians can be more successful going on the attack than conventional wisdom would expect.

\section{Not all stereotypes are created equal}

A politician's gender can provide voters with a decision-making heuristic, ${ }^{24}$ eliciting assumptions about policy positions and expected political performance. ${ }^{25}$ Identity cues allow for rapid inferences because they rely on stereotypes-mental schemas about a social group that provide certain expectations about the attributes, behaviors, and attitudes of group members. Thus, stereotypes provide a framework through which people interpret information about, and from, social others. ${ }^{26}$ Because stereotypes evoke numerous cognitive associations, however, different attributes may be called to mind at different times. Once a particular association has been activated, it becomes accessible and, therefore, likely to be employed when evaluating related information. The more accessible a specific stereotype feature, the more likely it will be used in subsequent evaluations. ${ }^{27}$ For example, in a context in which there is a need for compassion, a female would likely be evaluated as more competent. But if a situation called for assertiveness, a male would likely be deemed as more competent-while compassion would not even factor into a potential voter's evaluative process.

While some differences between the sexes can be explained by our evolutionary origins, gender stereotypes "refer to the meanings that individuals and societies ascribe to males and females." ${ }^{28}$ In the context of American politics, citizens have developed certain expectations about how male and female candidates will perform in office if elected. For example, voters typically view women as more liberal, ${ }^{29}$ honest, caring, kind, and affectionate. ${ }^{30}$ As a result, female politicians are expected to perform well on "compassion" issues, such as education, poverty, family issues, and the environment. ${ }^{31,32}$ Male candidates, on the other hand, are expected to be assertive, tough, independent, and competent as well as strong on "masculine" issues, such as national defense, crime, and the economy. The conventional wisdom is that female politicians face a "double bind," where voters favor politicians with masculine traits, but judge women unfairly when they display "counter-stereotypic" masculinity. ${ }^{33}$

As a result, much of the negative advertising literature starts from the assumption that women should not use attack ads because being aggressive is seen as 


\section{McLaughlin et al.}

masculine. Indeed, there is some evidence that female politicians are especially susceptible to backlash effects when they employ negative ads. ${ }^{34}$

However, we disagree with the conventional wisdom: the activation of gender stereotypes is contextdependent; therefore, there must be circumstances in which female politicians benefit from gender stereotypes when employing attack ads. While going on the attack can be seen as "masculine," negative ads are not always evaluated on the basis of whether they are "counter-stereotypic." Instead, evaluation of these ads may be driven by citizens' assumptions about whether a politician is credible when it comes to the issue at hand. Supporting this view, a growing body of literature has provided evidence that women do not face an inherent disadvantage for acting aggressively; female candidates often do not suffer a backlash or may actually stand to benefit from going on the attack. ${ }^{35,36}$

Gender stereotypes are complex, associative networks, and different gender associations may be activated for political evaluations at different times. When gender stereotypes favoring female candidates are primed, we expect that female politicians will be seen as more qualified than male politicians who go on the attack. If a female candidate attacks under these circumstances, then the attack should be seen warranted, at least compared to sponsorship by a male candidate.

\section{Sex, lies, and politics}

In this study, we measure candidate evaluations amid an informational context that should favor female politicians going on the attack-a political sex scandal. The majority of scholarly knowledge about political sex scandals has focused on Bill Clinton's affair with Monica Lewinsky. ${ }^{37}$ While this appeared to be an opportune time for Republicans to attack Clinton, Republican attacks backfired, largely because they were viewed as self-interested and transparently partisan. ${ }^{38}$ However, the recent fallout experienced by male political figures, including John Edwards, David Petraeus, Anthony Weiner, Arnold Schwarzenegger, and Herman Cain, suggests that the public does not always give promiscuous males a pass. Within this discussion about sex scandals and politics, the role of gender in shaping candidate evaluations is underexplored.

As alluded to above, there is good reason to expect that a political sex scandal would activate cognitive associations that are more favorable to female than male candidates. In general, people think that men are more likely to engage in extramarital affairs than women; ${ }^{39}$ the numbers show that they are, indeed, more likely. ${ }^{40}$ Evolutionary psychologists offer an explanation for this discrepancy-the differences in the sexual behavior and attitudes of males and females can be found in our ancestral past. ${ }^{41}$ From the perspective of enhancing reproductive success over generations, males largely had the goal of maximizing the number of genes they passed on and therefore looked for as many sexual partners as they could find. In addition, men have a documented propensity to pursue young, physically attractive partners. This is thought to be the result of youth and health signifying a higher likelihood of female fertility. ${ }^{42,43}$ Females, on the other hand, needed to focus on maximizing their offspring's chances of survival, and thus were more motivated to find a committed partner who would invest in supporting the child. ${ }^{44}$

These conflicting drives resulted in an "evolutionary arms race" 45 of sorts, where females endeavored to make males committed, males responded by learning to deceive females about their devotion, and females got better at spotting this deception. As a result, females developed a propensity to make inferences about the sincerity of a man's commitment, while males developed the tendency to occasionally "encourage a false reading" about their intended commitment. As humans moved into more organized, structured, and legally regulated environments, monogamy became more of the norm-but the imprints of evolution remain embedded in human psychology. As a result, discussions about sexual misconduct should be cognitively tied to assumptions and inferences about gender. Thus, a sex scandal may activate "gendered thinking," priming assumptions about the trustworthiness and devotion of females and at the same time activating thoughts about stereotypical male behaviors, including deception and infidelity.

Yet, the differences in the sexual behaviors of men and women are not just a result of evolution-they are also conditioned by the specific cultural environment in which gender stereotypes are developed. ${ }^{46}$ In the United States, there is plenty of high-profile, anecdotal evidence from the political arena to reinforce assumptions that males are more likely to pursue extramarital affairs. It follows that citizens should stereotype male politicians as more likely to engage in unfaithful and deceptive behavior. Further, female candidates should have more latitude to criticize an opponent caught in a sex scandal given the perception they might have greater empathy with the victim. Sex scandals, therefore, should prime cognitive associations that provide female politicians 


\section{When women attack}

with an opportunity to use gender stereotypes to their advantage. Thus, we predict that

H1a: When a politician sponsors an ad attacking an opponent caught in a sex scandal, citizens will evaluate the attacking candidate more favorably when the sponsor is female.

$\mathrm{H} 1 \mathrm{~b}$ : When a politician sponsors an ad attacking an opponent caught in a sex scandal, citizens will be more willing to vote for the attacking candidate when the sponsor is female.

\section{Voter gender as a moderating factor}

Mental schemas about politics and gender vary by individual. Although people are typically socialized (for better or worse) to have consistent stereotypes about social groups, ${ }^{47}$ the specific associative networks that constitute a schema will vary from person to person. ${ }^{48}$ In particular, assumptions about particular groups, such as a political party, will vary widely based on whether a person is a member of that group. ${ }^{49}$ Therefore, the effects of gender cues should depend on a voter's gender.

A large body of literature has shown that that female voters are more likely to support female politicians. ${ }^{50,51,52,53,54}$ This "gender affinity" perspective argues that women are more motivated to support female candidates than male candidates. This tendency, in part, can be explained by underrepresentation: many female voters want to see their gender equally represented in office and are cognizant that this is not currently the case. ${ }^{55}$

There is less evidence, however, that males are similarly motivated to vote based on gender-related considerations. ${ }^{56}$ This is likely a result of males being overrepresented in the political arena. Because male politicians represent the "status quo," there is little reason for male voters to give much thought to a male politician's gender-it is taken for granted. Thus, in the context of politics, gender should be a more salient cue for females because they are in the political minority.

Further, against the backdrop of a sex scandal, there is reason to believe that female voters would be particularly punitive toward males who go on the attack, while male voters should lack the same motivation. If females are attuned to detect male betrayal and deception, discussion about sexual misconduct should prime female respondents to be alert and raise suspicions about the trustworthiness of what a male candidate says or does. For female voters, a sex scandal should activate suspicions of male misconduct and lead to attributions of a scandalized male candidate's actions as deceptive or self-interested. Conversely, female voters should be more likely to view a female candidate as trustworthy. Thus, we predict that

$\mathrm{H} 2 \mathrm{a}$ : When a politician sponsors an ad attacking an opponent caught in a sex scandal, female respondents will evaluate the attacking candidate more favorably when the sponsor is female as opposed to male.

$\mathrm{H} 2 \mathrm{~b}$ : When a politician sponsors an ad attacking an opponent caught in a sex scandal, female respondents will be more willing to vote for the attacking candidate when the sponsor is female as opposed to male.

Although we do not expect male respondents to be similarly motivated by gender cues, it is important to test whether or not males, in fact, show gender affinity. We therefore ask

RQ1a: When a politician sponsors an ad attacking an opponent caught in a sex scandal, will male respondents evaluate the attacking candidate more favorably when the sponsor is male?

RQ1b: When a politician sponsors an ad attacking an opponent caught in a sex scandal, will male respondents be more willing to vote for the attacking candidate when the sponsor is male?

\section{"Masculine" Republicans and "feminine" Democrats}

The effect of gender cues should depend not just on message recipient sex; they should also be influenced by other source cues, such as a candidate's party affiliation. Scholars have become increasingly interested in the reciprocal influence of gender and party affiliation, but there is a lack of consensus on whether and how gender interacts with partisan identification to affect voter opinions. Some scholars argue that partisanship can overwhelm the effects of gender; ${ }^{57}$ others claim that the influence of gender cues is contingent on partisan cues. Still others find that gender cues transcend partisan cues. ${ }^{58}$ Thus, the relationship between gender and party affiliation is likely context dependent. We contend that in a context in which gender stereotypes favor females, candidates will be more likely to receive a gender boost when they are identified as Democratic than when they are identified as Republican.

Democrats should have an advantage in these scenarios because the Democratic Party is typically imbued with more "feminine" stereotypes, while the Republican Party is stereotyped as more "masculine." 59 Therefore, female Democrats should be especially likely to 


\section{McLaughlin et al.}

benefit from the activation of specific cognitive associations about femininity. Female Republicans, on the other hand, may less consistently activate-and benefit from-feminine stereotypes applied to political evaluations.

While some gender stereotypes are deeply engrained in human psychology, the associations between the political parties and gender are more fluid and contextual. There have been, however, clear trends over the last several decades linking the Republican Party with masculine frames and the Democratic Party with feminine frames. First, Democrats have largely taken policy stances that are protective of women's rights, such as on abortion and equal pay. Second, the Democratic Party has a larger proportion of female representatives in elective office and significantly more support from female voters. Finally, Republican presidential candidates have been more successful in framing themselves as masculine than their Democratic counterparts.

More significantly, there are implicit, cognitive connections between gender and party. For example, research demonstrates that people unconsciously associate the Democratic Party with feminine words and the Republican Party with masculine words that are completely unrelated to politics. Winter argues that these two social categories are intertwined in citizens' minds and that "a candidate's party affiliation might influence voters' perceptions of his or her enactment of masculinity and femininity." "60 For example, if a female politician does something stereotypically "feminine," such as talk about the importance of educating and nurturing America's youth, this overture might be interpreted quite differently depending on whether the politician is Democrat or Republican. When gender stereotypes are primed, female Democrats should be more likely to be judged through the lens of femininity than female Republicans.

In scenarios in which gender stereotypes favor women, female Democrats are more likely to be seen as a credible embodiment of feminine attributes than female Republicans. In the context of a sex scandal, therefore, a female Democrat should find it easier to convince voters that she is credible on compassion and family issues, thereby making an attack on her opponent seem motivated by a genuine concern and empathy for the scandal victim. A female Republican, on the other hand, might not incur the same benefit under these circumstances because the cues from her party are more prone to activate masculine associations, which might make her attack seem politically motivated. As a result, we predict that

H3a: When a female politician sponsors an ad attacking a male opponent caught in a sex scandal, respondents will evaluate the attacking candidate more favorably when the sponsor is a Democrat as opposed to a Republican.

$\mathrm{H} 3 \mathrm{~b}$ : When a female politician sponsors an ad attacking a male opponent caught in a sex scandal, respondents will be more willing to vote for the attacking candidate when the sponsor is a Democrat as opposed to a Republican.

\section{Method}

\section{Sample}

Participants were recruited through Survey Sampling International (SSI), an online sample provider. SSI utilizes a variety of recruitment techniques to provide " $\mathrm{di}$ verse, robust yet consistent samples to support high quality research data." ${ }^{\prime 1}$ SSI strives to achieve nationally representative samples, and their recruiting method includes multiple levels of randomization. A total of 599 U.S. adults took part in this experiment. Respondents were distributed across 44 states. Ages ranged from 18 to $83(M=48.47, S D=16.59)$. The sample was 51.9 percent female, 78.3 percent white, 9.5 percent black, 6.3 percent Asian, and 9.2 percent Hispanic. Party identification was 40.4 percent Democrat, 25.5 percent Republican, 26.0 percent Independent. Levels of education were: 3.2 percent some high school, 22.4 percent high school graduate, 36.8 percent some college, 28.1 percent college graduate, and 9.6 percent post-graduate degree.

\section{Experimental procedure}

To test the effects of gender and partisan affiliation, we employed a $2 \times 2$ between-subjects factorial design. The factors were attack sponsor gender (male, female) and attack sponsor party (Democrat, Republican).

Participants were randomly assigned to view one of four versions of a fictitious news story about a sex scandal involving a male congressional candidate named Sean Townsend, an incumbent state senator in Colorado's fourth district. The story reported on Townsend's "sexting" of a young female campaign intern. Participants first received a prompt informing them they were about to read an e-mail "currently circulating in Colorado" sent by Townsend's opponent. Because campaigns increasingly rely on e-mail 


\section{When women attack}

as a means of delivering political messages, e-mail was deemed an appropriate medium for delivering the political attack ad seen by respondents.

The language in all e-mail conditions was exactly the same except for the gender of the sponsor and the political party of each candidate. In one condition the e-mail was sponsored by a male candidate (Alan Baker), and in the other condition by a female candidate (Elizabeth Baker). The party of each candidate also rotated between Republican and Democrat, as shown in Table 1.

The e-mail attacked Townsend for his inappropriate sexting behavior, calling him unfit for office and asking for donations to help defeat him. The e-mail also contained a link to a video of a news story covering the scandal, which participants viewed after clicking "continue" (see Appendix A for the full transcript).

\section{Video stimulus}

To produce the news story, a professional actor was hired to fill the role of news anchor. The script mirrored a typical television news story in format and length (1:47). A television studio with a green screen was used to tape the mock program. A professional director and experienced video editor assisted in the development and production of the scripts. The video was therefore able to convincingly mimic the type of coverage that would be found on a local news station.

The news story opened by introducing the scandal, saying Sean Townsend was accused of sending inappropriate text messages to a 23 -year-old female intern. The story highlighted that Townsend was in a "dead heat" with Baker (Alan or Elizabeth) in the race for Colorado's fourth district Congressional seat. The video included screen captures of three texts, all of which were designed to be sexually suggestive without being excessively graphic (see Figure 1).

After viewing the video, participants filled out a posttest questionnaire, which asked them to evaluate both candidates, as well as answer some basic demographic questions. The dependent measures are described below. Participants then saw a debriefing screen and were thanked for their time.

\section{Dependent measures}

Candidate favorability. Favorability toward the attack sponsor (Alan or Elizabeth Baker) was measured using a 100-point feeling thermometer, with 0 representing a "cold" or unfavorable feeling and 100 representing a "warm" or favorable feeling $(M=49.16, S D=24.48)$.
Table 1. Experimental conditions.

\begin{tabular}{|c|c|c|c|c|c|}
\hline \multirow[b]{2}{*}{ Condition } & \multirow[b]{2}{*}{$N$} & \multicolumn{2}{|c|}{ Baker } & \multicolumn{2}{|c|}{ Townsend } \\
\hline & & Gender & Party & Gender & Party \\
\hline 1 & 150 & Male & Democrat & Male & Republican \\
\hline 2 & 151 & Male & Republican & Male & Democrat \\
\hline 3 & 149 & Female & Democrat & Male & Republican \\
\hline 4 & 148 & Female & Republican & Male & Democrat \\
\hline
\end{tabular}

Willingness to vote. A second measure asked participants whether they would be willing to vote for the ad sponsor (Alan or Elizabeth Baker) if they were to run for Congress in their district. Responses were also measured using a 100 -point scale $(M=47.62, S D=28.56)$.

\section{Analysis strategy}

One-way analysis of variance (ANOVA) was used to test the main effects of the e-mail sponsor's gender, the effects of candidate gender among female participants, the effects of candidate gender among male participants, and the effects of candidate party affiliation for the female candidate. One-tailed tests were performed for all directional hypotheses. Because our hypotheses predicted directional and not interactive effects, we used split files to isolate the effects of gender among male and female participants, as well as the effects of partisan identification on the female sponsor.

\section{Results}

\section{Main effects of politician gender}

Results revealed a significant main effect of the sponsor's gender on favorability toward the sponsor, $F(1,583)=3.33, \eta^{2}=0.01, p=0.03$, with the attack sponsor being viewed as significantly more favorable when female $(M=51.10, S E=1.42)$ compared to male $(M=47.42, S E=1.43)$. Therefore, H1a was supported (see Figure 2).

Additionally, there was a significant main effect of candidate gender on willingness to vote for the sponsor $F(1,578)=2.58, \eta^{2}=0.003, p=0.05$. Specifically, participants expressed more willingness to vote for the attack sponsor when the sponsor was female $(M=$ $49.58, S E=1.67)$ compared to when the sponsor was male $(M=45.77, S E=1.67)$. H1b was thus supported.

\section{Gender effects}

Hypothesis 2 predicted that females would respond more positively to attack ads coming from members 


\section{McLaughlin et al.}

\section{Screen capture 1}

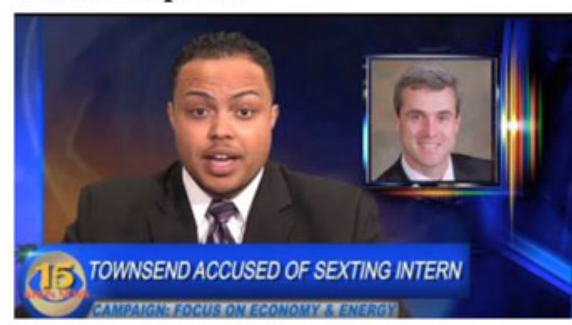

Screen capture 3

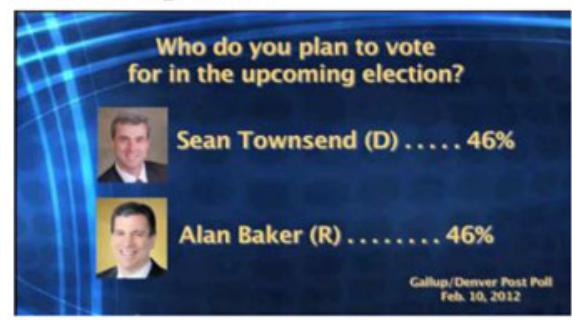

Screen capture 2

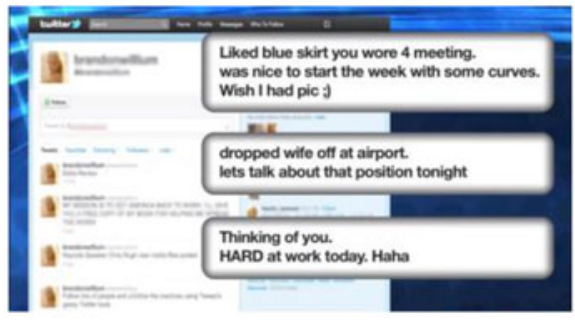

\section{Screen capture 4}

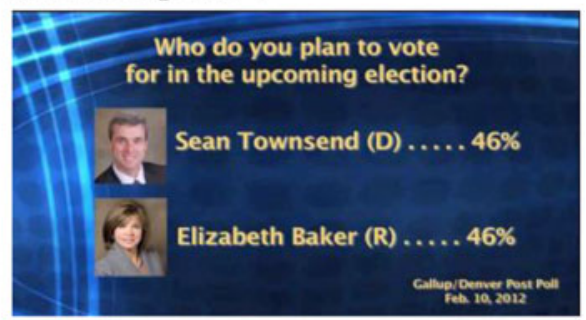

Figure 1. News story screen captures. Note: Screen capture 1 displays the KRDN-13 News anchor introducing the political scandal, along with a picture of candidate Sean Townsend. Screen capture 2 displays the text messages, taken from a Twitter feed, sent by Townsend to the female intern. Screen capture 3 displays a public opinion poll showing Townsend in a "dead-heat" with male opponent Alan Baker. Screen capture 4 displays a public opinion poll showing Townsend in a "dead-heat" with female opponent Elizabeth Baker.

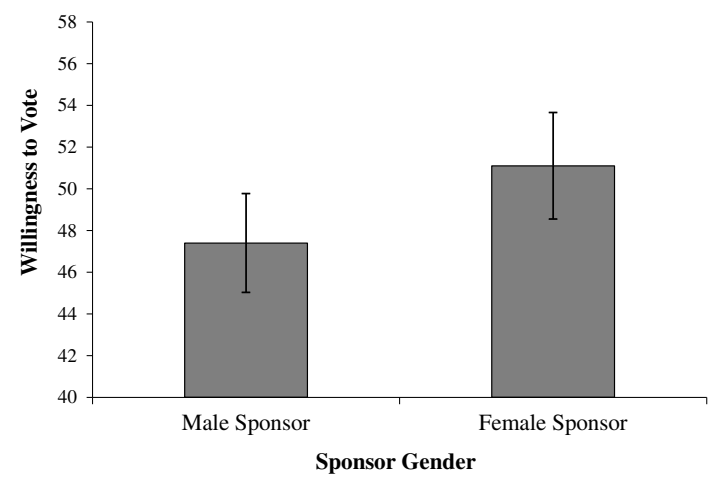

Figure 2. Willingness to vote for attack ad sponsor by sponsor gender.

of their own gender. In line with these expectations, we found that female participants (a) viewed the female sponsor of the attack ad significantly more favorably $(M=53.46, S E=2.03)$ than the male sponsor $(M=45.56, S E=1.93), F(1,298)=8.07, \eta^{2}=0.03$, $p=0.003$, and (b) were significantly more willing to vote for the female sponsor $(M=51.75, S E=2.35)$ compared to the male sponsor $(M=45.01, S E=2.23)$,

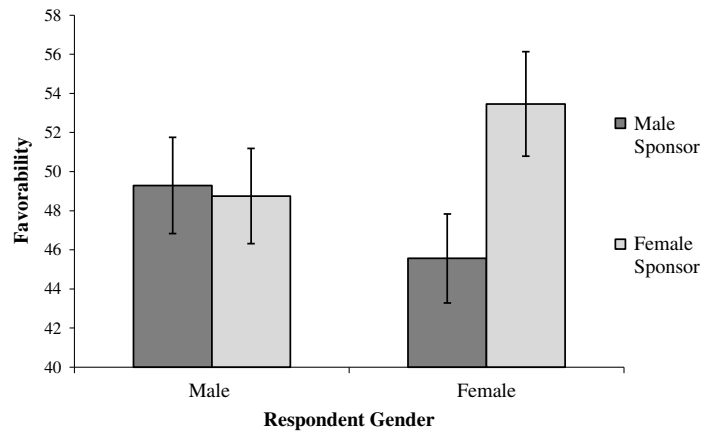

Figure 3. Favorability toward attack ad sponsor by sponsor and participant gender.

$F(1,298)=4.33, \eta^{2}=0.01, p=0.019$. We therefore found support for $\mathrm{H} 2 \mathrm{a}$ and $\mathrm{H} 2 \mathrm{~b}$.

Research question 1 asked whether or not male participants would respond more positively to an attack ad coming from a male candidate. Our results did not reveal any evidence of male gender affinity: male participants were not more likely to (a) view a male candidate more favorably than a female candidate 


\section{When women attack}

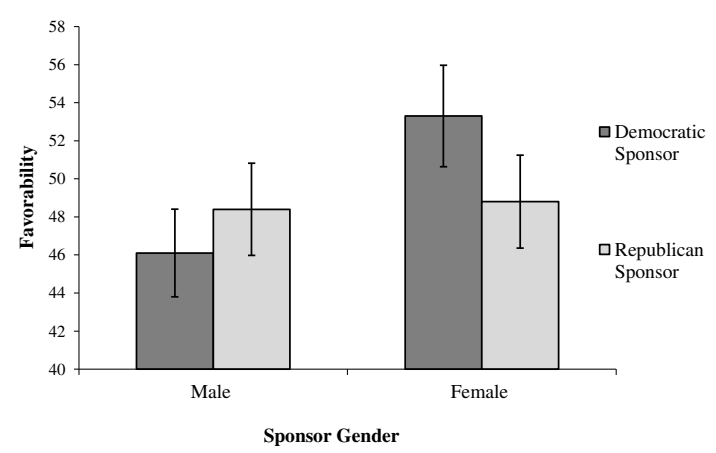

Figure 4. Favorability toward attack ad sponsor by sponsor gender and party.

$F(1,280)=0.03, \eta^{2}=0.00$, n.s., nor were they $(\mathrm{b})$ more willing to vote for a male candidate than a female candidate $F(1,280)=0.06, \eta^{2}=0.00, n . s$. Thus, we find that while female respondents are more likely to support a female candidate going on the attack, male citizens do not seem to be affected by sponsor gender.

\section{Partisanship and female candidates}

Hypothesis 3 tests whether female candidates are more successful when they go on the attack when they are identified as Democratic as opposed to Republican. Our results reveal that Democratic sponsors are (a) viewed marginally more favorably $(M=53.32$, $S E=2.01)$ than Republican sponsors $(M=48.79$, $S E=2.01), F(1,292)=2.42, \eta^{2}=0.02, p=0.06$. Additionally, participants were (b) significantly more willing to vote for a female sponsor when she was identified as a Democrat $(M=52.31, S E=2.35)$ than a Republican $(M=46.68, S E=2.35), F(1,291)=4.37$, $\eta^{2}=0.04, p=0.05$ (see Table 2, Figure 4). Thus, we find partial support for $\mathrm{H} 4 \mathrm{a}$ and support for $\mathrm{H} 4 \mathrm{~b}$. The results show that female candidates are more likely to be successful going on the attack during a sex scandal when they are Democrats compared to when they are Republican. (Supplemental analysis found no significant effect of party affiliation among male sponsors.)

\section{Discussion}

Although scholars have largely assumed that female politicians cannot go on the attack without suffering backlash effects due to gender stereotypes, this study presents evidence that there are circumstances in which gender stereotypes will actually favor female politicians
Table 2. Favorability and willingness to vote by experimental factors.

\begin{tabular}{|c|c|c|c|}
\hline & $F$ & $\eta^{2}$ & Power \\
\hline \multicolumn{4}{|l|}{ Favorability } \\
\hline Candidate gender & $3.33^{*}$ & 0.01 & 0.47 \\
\hline Candidate gender (female participants) & $8.07^{* *}$ & 0.03 & 0.81 \\
\hline Candidate gender (male participants) & 0.00 & 0.00 & 0.54 \\
\hline Female candidate $\times$ party & $2.42^{\dagger}$ & 0.02 & 0.39 \\
\hline \multicolumn{4}{|c|}{ Willingness to vote } \\
\hline Candidate gender & $2.58^{*}$ & 0.01 & 0.36 \\
\hline Candidate gender (female participants) & $4.33^{* *}$ & 0.01 & 0.53 \\
\hline Candidate gender (male participants) & 0.06 & 0.00 & 0.56 \\
\hline Female candidate $\times$ party & $4.37^{*}$ & 0.04 & 0.42 \\
\hline
\end{tabular}

going negative. We tested this expectation by producing a television news story where a fictitious politician (Sean Townsend) had come under fire for sending inappropriate texts to a female intern. Participants also viewed an attack e-mail from Townsend's opponent, whose gender and party affiliation were manipulated. The findings of this study further our understanding of how gender stereotypes influence the outcome of political attack ads, clarifying the relationship between the sponsoring candidate's gender and the voter's gender, the relationship between the sponsoring candidate's gender and partisan affiliation, and the role of gender in assessing the fallout from a political sex scandal.

First, we found consistent evidence that, in the right circumstances, female candidates will be better positioned to go on the attack than male candidates. When a political candidate attacked an opponent caught in a sex scandal, voters viewed the sponsor more favorably, and expressed more willingness to vote for the sponsor, when the candidate was female compared to male. These results add to a fairly substantial body of literature showing that female politicians can successfully go on the attack without suffering a backlash. This literature, however, has not clearly specified the conditions under which female politicians can effectively go negative. Our results support the expectation that in a context in which gender stereotypes favor female over male candidates, women will have more to gain when going on the attack.

Much previous research has worked from the assumption that going on the attack will be viewed as masculine behavior, thus being counterstereotypic (and ill-advised) for women. But gender stereotypes are complex and multifaceted constructs; therefore, which stereotypes are activated and made salient for 


\section{McLaughlin et al.}

subsequent evaluations should depend upon the specific context. In this case, sex scandals should activate cognitive associations engrained in human psychology over the millennia, associations that receive cultural reinforcement through news reports of a male politician's misbehavior. In terms of stereotypes, political sex scandals should activate assumptions about males being deceptive and unfaithful and females being nurturing, honest, and committed. Once activated, these mental associations should then be used in subsequent evaluations of new political information, allowing females to be seen as more trustworthy and justified in going negative.

We do not expect the results of our study to generalize to all other political scandals. Whether a female candidate can successfully go on the attack should depend first upon whether gender stereotypes are activated and then, if they are, which stereotypes are at play. Political scandals may bring to mind a wide range of relevant factors for the evaluation of political information. Thus, it would be useful for future research to more systematically evaluate the circumstances in which gender stereotypes hurt, help, or do not matter for female candidates looking to go on the attack.

Second, the results of this study illustrate that the effectiveness of an attack ad may be contingent on respondent gender. Among female respondents, we found that the sponsoring candidate was evaluated more favorably when female as opposed to male. We found no difference in the effect of sponsor gender among male participants, however. These findings are consistent with the gender affinity literature, which has demonstrated that female voters tend to support female candidates; there is much less evidence that male voters are similarly predisposed to vote for males. In the context of a sex scandal in particular, gender stereotype activation should be more salient for females than males. Because the female mind is attuned to detect male betrayal and deception, discussion about sexual misconduct should prime females to be alert and suspicious about male trustworthiness.

Third, we found that gender effects of attack ad sponsorship are also contingent on partisan affiliation. In regard to favorability and willingness to vote, our results show that Democratic females stand to benefit most from going on the attack. These findings matched our expectations that in circumstances where female politicians stand to benefit from gender stereotypes, as during a political sex scandal involving an offending male, Democratic females are better served because they are cognitively associated with femininity, while Republican females are associated with masculinity. In practical terms, female Democrats should therefore promote the use of messaging and imagery that activates specific cognitive networks about femininity. Female Republicans, on the other hand, may not benefit, or benefit as much, from using tactics that activate stereotypes about femininity, according to our findings. Thus, when gender stereotypes that favor females are activated, female candidates on the Democratic side should be in better position to appear credible going on the attack than Republicans.

Finally, this study advances our knowledge about the role that gender plays in political sex scandals. The results appear to both corroborate the claim that attacking during a political sex scandal can result in a backlash, as Republicans found during the ClintonLewinsky sex scandal, and further clarify the conditions in which this is likely to be the case. Our findings suggest that female candidates can go on the attack in the context of a sex scandal without suffering a backlash, but female Democrats are in the best position to do so. We did not find any evidence that male candidates stand to benefit from going on the attack during a sex scandal; indeed, we see evidence that male politicians can suffer a backlash. Women candidates are less likely to experience a backlash, but we did not find evidence that Republican females stand to benefit by going on the attack.

As with any empirical research, there are some important limitations to acknowledge with this study. Perhaps most significantly, we did not directly measure whether gender stereotypes were activated. The interpretation of our results, therefore, also relies on an assumption-that gender stereotypes were in fact primed and used for evaluation. Given that our results line up with theoretical expectations, we do think there is reason to believe that gender stereotypes are at play. But more research that directly tests this assumption is necessary to fully demonstrate if, and how, gender stereotypes can provide an advantage for female politicians looking to go on the attack.

Additionally, because we used fictitious candidates, our study lacked the real-world context in which citizens are familiar with the political actors involved. How gender and party cues influence voter evaluations is likely to depend on other traits and characteristics as well. For example, prominent female politicians, such as Hillary Clinton, will have familiar personality characteristics and a political track record that will be front 


\section{When women attack}

and center in the minds of voters. A candidate like Clinton must work within the confines of gender stereotypes, but gender cues should play out differently when a politician is well known. In Clinton's case, it is likely that people are now predisposed to employ certain gender stereotypes when evaluating her political messages. As a result, the gender stereotypes used to evaluate a politician like Clinton should have more to do with what voters think about her as a candidate than the specific news context. For example, when Clinton experienced a widely replayed "emotional moment" on the campaign trail in 2008, many political analysts debated whether it was calculated or sincere, rather than just evaluating it as a display of femininity.

Conversely, the gender stereotypes employed to evaluate a female politician with a lesser-known track record should be more context-dependent. Thus, the expectations presented here may play out differently depending on the specific candidate in question. Still, the sacrifice in ecological validity was considered necessary here to isolate the effects of gender and partisan cues. Our results offer a sense of how these factors would be expected to play out, all things being equal.

One final limitation worth noting is that some of our results, while significant, did not result in dramatic differences in favorability and likelihood to vote. For example, the main effect of gender resulted in about a 4-point difference for favorability and likelihood to vote (although other tests had larger mean differences). While at first glance these mean differences may not seem particularly substantial, in light of the fact that some elections are decided by a few percentage points, a 4-point change in likelihood to vote could make all the difference in who wins an election, especially a deadheat race like the fictional one presented here.

\section{Conclusion}

In this study we provided evidence that under certain circumstances, gender stereotypes will favor female politicians going on the attack. These findings help make sense of the inconsistent findings in the candidate gender and attack ad literatures-some of which have claimed female candidates can successfully go on the attack, some of which have claimed female candidates will inevitably face repercussions for going negative, and some of which have found that gender makes no difference when it comes to attack advertising. Our study suggests that these results will be contingent upon whether gender stereotypes are activated and, if so, which stereotypes are activated. Additionally, the effect of gender cues should depend both on voter gender and candidate political affiliation.

Against the backdrop of a political sex scandal, a context that should activate gender stereotypes that favor female candidates, we have evaluated the interplay between gender and partisan identity on citizen reactions to a political attack ad. The results of our study shed light on the circumstances in which female candidates can successfully go on the attack, as well as the contingent conditions surrounding gender cues. Ultimately, the conventional wisdom that female politicians cannot engage in aggressive messaging without suffering a backlash appears unfounded, although a wide range of factors can affect how different voter segments may react to a female candidate going on the attack.

Gender dynamics play an important role in campaigns and electoral behavior. With the growing number of female candidates in elections and the persistence of gender-based issues in electoral debate, it is imperative to detail the conditions by which gender plays a role in elections and systematically investigate its meaning for democracy. Particularly important to consider is the role gender plays in political attack advertising. This study takes us a step closer to understanding how gender stereotypes affect political outcomes as American politics become increasingly divisive.

\section{References}

1. Kathleen Dolan and Timothy Lynch, "It takes a survey: Understanding gender stereotypes, abstract attitudes, and voting for women candidates," American Politics Research, 2014, 42(4): 656-676.

2. Richard L. Fox and Eric Smith, "The role of candidate sex in voter decision making," Political Psychology, 1998, 19(2): 405-415.

3. Nichole M. Bauer, "Rethinking stereotype reliance: Understanding the connection between female candidates and gender stereotypes," Politics and the Life Sciences, 2013, 32(1): 22-42.

4. Deborah J. Brooks, He Runs, She Runs: Why Gender Stereotypes Do Not Harm Women Candidates (Princeton, NJ: Princeton University Press, 2013).

5. Kathleen Dolan, "The impact of candidate sex on evaluations of candidates for the U.S. House of Representatives," Social Science Quarterly, 2004, 85(1): 206-217. 


\section{McLaughlin et al.}

6. Victoria L. Brescoll and Eric. L. Uhlmann, "Can angry women get ahead? Status conferral, gender, and expression of emotion in the workplace," Psychological Science, 2008, 19(3): 268-275.

7. Paul S. Herrnson, Celeste J. Lay, and Ativa A. Stokes, "Women running as women: Candidates' gender, campaign issues, and voter targeting strategies," Journal of Politics, 2003, 65(1): 1-24.

8. Kathleen H. Jamieson, Beyond the Double Bind: Women and Leadership (New York: Oxford University Press, 1995).

9. Ann Gordon, David Shafie, and Ann N. Crigler, "Is negative advertising effective for female candidates? An experiment in voters' uses of gender stereotypes," Harvard International Journal of Press/Politics, 2003, 8(3): 35-53.

10. Virgina Sapiro, "If Senator Baker were a woman: An experimental study of candidate images," Political Psychology, 1981-82, 3(1): 61-83.

11. Anne Johnston Wadsworth, Philip Patterson, Lynda Lee Kaid, Ginger Cullers, Drew Malcomb, and Linda Lamirand, “'Masculine' vs. 'feminine' strategies in political ads: Implications for female candidates," Journal of Applied Communication Research, 1987, 15(1): 77-94.

12. Yanna Krupnikov and Nicole M. Bauer, "The relationship between campaign negativity, gender and campaign context," Political Behavior, 2014, 36(1): 167-188.

13. John G. Geer, In Defense of Negativity: Attack Ads in Presidential Campaigns (Chicago: University of Chicago Press, 2006).

14. Gina M. Garramone, "Effects of negative political advertising: The roles of sponsor and rebuttal," Journal of Broadcasting and Electronic Media, 1995, 29(2): 147-159.

15. Gina M. Garramone and Charles K. Atkin, "Effects of negative political advertising on the political process," Journal of Broadcasting and Electronic Media, 1990, 34(3): 299-311.

16. Richard R. Lau, Lee Sigelman, and Ivy Brown Rovner, "The effects of negative political campaigns: A meta-analytic reassessment," Journal of Politics, 2007, 69(4): 1176-1209.

17. James D. King and Jason B. McConnell, "The effect of negative campaign advertising on vote choice: The mediating influence of gender," Social Science Quarterly, 2003, 84(4): 843-857.

18. Amy F. Jasperson and David Fan, "An aggregate examination of the backlash effect in political advertising: The case of the 1996 U.S. Senate race in Minnesota," Journal of Advertising, 2002, 31(1): 1-12.
19. David A. M. Peterson and Paul A. Djupe, "When primary campaigns go negative: The determinants of campaign negativity," Political Research Quarterly, 2005, 58(1): $45-54$.

20. Scott Althaus and Young Mie Kim, "Priming effects in complex information environments: Reassessing the impact of news discourse on presidential approval," Journal of Politics, 2006, 68(4): 960-976.

21. Robert Wright, The Moral Animal: Why We Are, the Way We Are: The New Science of Evolutionary Psychology (New York: Vintage, 1995).

22. Nicholas J. G. Winter, "Masculine Republicans and feminine Democrats: Gender and Americans' explicit and implicit images of the political parties," Political Behavior, 2010, 32(4): 587-618.

23. Kathleen Dolan, "Is there a 'gender affinity effect' in American politics? Information, affect, and candidate sex in U.S House elections," Political Research Quarterly, 2008, 61(1): 79-89.

24. Leonie Huddy and Nayda Terkildsen, "Gender stereotypes and the perception of male and female candidates," American Journal of Political Science, 1993, 37(1): 119-147.

25. Jacqueline C. Hitchon and Ching Ching Chang, "Effects of gender schematic processing on the reception of political commercials for men and women candidates," Communication Research, 1995, 22(4): 430-458.

26. Kim L. Fridkin, Patrick J. Kenney, and Gina Serignese Woodall, "Bad for men, better for women: The impact of stereotypes during negative campaigns," Political Behavior, 2009, 31(1): 53-77.

27. Danny Hayes, "When gender and party collide: Stereotyping in candidate trait attribution," Politics and Gender, 2011, 7(2): 133-165.

28. Alice H. Eagly and Wendy Wood, "The nature-nurture debates: 25 years of challenges in understanding the psychology of gender," Perspectives on Psychological Science, 2013, $8(3): 340-357$, at 350.

29. Leonie Huddy and Tony E. Carey, "Group politics redux: Race and gender in the 2008 Democratic presidential primaries," Politics \& Gender, 2009, 5(1): 81-96.

30. Kim Fridkin and Patrick J. Kenney, "The role of gender stereotypes in U.S. Senate campaigns," Politics \& Gender, 2009, 5(3): 301-329.

31. Alice H. Eagly and Steven J. Karau, "Role congruity theory of prejudice toward female leaders," Psychological Review, 2002, 109(3): 573-598. 


\section{When women attack}

32. Brittany L. Stalsburg, "Voting for mom: The political consequences of being a parent for male and female candidates," Politics \& Gender, 2010, 6(3): 373-404.

33. Melissa K. Miller, Jeffrey S. Peake, and Brittany Boulton, "Testing the Saturday Night Live hypothesis: Fairness and bias in newspaper coverage of Hillary Clinton's presidential campaign," Politics \& Gender, 2011, 6(2): 169-198.

34. Paul S. Herrnson and Jennifer C. Lucas, "The fairer sex? Gender and negative campaigning in U.S. elections," American Politics Research, 2006, 34(1): 9-94.

35. Lynda L. Kaid, Sandra L. Myers, Val Pipps, and Jan Hunter, "Sex role perceptions and televised political advertising: Comparing male and female candidates," Women and Politics, 1984, 4(4): 41-53.

36. Seth Thompson and Janie Steckenrider, "Gender stereotypes and decision context in the evaluation of political candidates," Women and Politics, 1997, 17(4): 71-92.

37. Spiro Kiousis, "Job approval and favorability: The impact of media attention to the Monica Lewinsky scandal on public opinion of President Bill Clinton," Mass Communication and Society, 2003, 6(4): 435-451.

38. Dhavan V. Shah, Mark D. Watts, David Domke, and David P. Fan, "News framing and cueing of issue regimes: Explaining Clinton's public approval in spite of scandal," Public Opinion Quarterly, 2002, 66(3): 339-370.

39. Scott L. Coltrane and Randall Collins, Sociology of Marriage and the Family: Gender, Love, and Property, 4th ed. (Chicago: Nelson-Hall, 1995).

40. Edward O. Laumann, John H. Gagnon, Robert T. Michael, and Stuart Michaels, The Social Organization of Sexuality: Sexual Practices in the United States (Chicago: University of Chicago Press, 1994).

41. David M. Buss, The Evolution of Desire: Strategies of Human Mating (New York: Basic Books, 1994).

42. Robert Ervin Cramer, Jeffrey T. Schaefer, and Suzanne Reid, "Identifying the ideal mate: More evidence for male/female convergence," Current Psychology, 1996, 15(2): 157-166.

43. Susan Sprecher, "The importance to males and females of physical attractiveness, earning potential, and expressiveness in initial attraction," Sex Roles, 1989, 21(9): 591-607.

44. Donald Symons, The Evolution of Human Sexuality (New York: Oxford University Press, 1979).

45. Wright, 63.

46. Eagly and Wood.
47. Sandra L. Bem, "Gender schema theory: A cognitive account of sex typing," Psychological Review, 1981, 88(4): 354-364.

48. Roger D. Masters, The Nature of Politics (New Haven, CT: Yale University Press, 1989).

49. Richard Jenkins, Social Identity, 3rd ed. (New York: Routledge, 2008).

50. Craig Leonard Brians, "Women for women? Gender and party bias in voting for female candidates," American Politics Research, 2005, 33(3): 357-375.

51. Elizabeth Adell Cook, "Voter responses to women candidates," in The Year of the Woman: Myths and Realities, Elizabeth Adell Cook, Sue Thomas, and Clyde Wilcox, eds. (Boulder, CO: Westview, 1994), pp. 217-236.

52. Kathleen Dolan, "Voting for women in the 'Year of the Woman," American Journal of Political Science, 1998, 42(1): 272-293.

53. Eric Plutzer and John F. Zipp, "Identity politics, partisanship, and voting for women candidates," Public Opinion Quarterly, 1996, 60(1): 30-57.

54. Kira Sanbonmatsu, "Gender stereotypes and vote choice," American Journal of Political Science, 2002, 46(1): 20-34.

55. Elizabeth Goodyear-Grant and Julie Croskill, "Gender affinity effects in vote choice in Westiminister systems: Assessing 'flexible' voters in Canada," Politics \& Gender, 2011, 7(2): 223-250.

56. Cindy Simon Rosenthal, "The role of gender in descriptive representation," Political Research Quarterly, 1995, 48(3): 599-611.

57. Leonie Huddy and Theresa Capelos, "Gender stereotyping and candidate evaluation: Good news and bad news for women politicians," in The Social Psychology of Politics, Victor C. Ottati, R. Scott Tindale, John Edwards, Fred B. Bryant, Linda Heath, Yolanda Suarez-Balcazar, and Emil J. Posavac, eds. (New York: Kluwer Academic Press, 2002), pp. 29-53.

58. Kira Sanbonmastsu and Kathleen Dolan, "Do gender stereotypes transcend party?," Political Research Quarterly, 2009, 62(3): 485-494.

59. George Lakoff, Moral Politics: How Liberals and Conservatives Think (Chicago: University of Chicago Press, 2002).

60. Winter, 609.

61. Survey Sampling International, http://www.surveysamp ling.com/. 


\section{McLaughlin et al.}

\section{Appendix A}

\section{Attack e-mail transcript}

Dear

Have you seen the shocking text messages that Democratic [Republican] congressional candidate Sean Townsend was accused of sending to his young female intern last week? Sexually harassing a 23-year-old intern!?! Townsend clearly has no respect for women in the workplace and is a DISGRACE to the great state of Colorado.

\section{Townsend has no business running for Congress!}

Help spread the word about Townsend's inappropriate behavior:

- Watch the news clip about Townsend's text messages.

- Share it with your friends and family.

- Donate now to help defeat Townsend.

Our politicians should be focusing on making America strong, not using their power in reprehensible ways. With so much work to be done to get America back on track, we don't have time for this nonsense!

Colorado deserves better. You deserve better. Vote Alan [Elizabeth] Baker for Congress.

Sincerely, Alan [Elizabeth] Baker

\section{Appendix B}

\section{News video transcript}

Republican [Democratic] U.S. congressional candidate Sean Townsend's campaign was rocked today by allegations that he sent inappropriate text messages to a 23-year-old female intern.
This accusation comes as Townsend is in a dead heat with Democrat [Republican] State Representative Alan [Elizabeth] Baker in the race for Colorado's fourth district congressional seat

[GRAPHIC]

A recent Gallup/Denver Post poll shows Townsend in a virtual tie with Baker.

Townsend, a current state senator, has campaigned heavily on the issues of energy independence and economic revitalization.

KRDN-13 News obtained the texts early this morning after a source close to the intern posted them on Twitter.

The source characterized the texts as sexually suggestive.

[GRAPHIC]

In one text he wrote:

Liked blue skirt you wore 4 meeting. was nice to start the week with some curves. Wish I had pic ;)

Another reads:

dropped wife off at airport. lets talk about that position tonight

Yet another reads:

Thinking of you. HARD at work today. Haha

When KRDN-13 contacted the Townsend Campaign about the allegations, the Senator had no comment, and said that Townsend wants to remain focused on the issues. This is his first time running for Congress after serving in the state legislature for eight years.

Political analysts have been predicting a close race between Townsend and Baker.

Townsend has recently raised just over 1 million dollars in the last financial quarter, in line with the roughly 1 million dollars Baker has raised.

Townsend is scheduled to appear at a fundraiser this weekend in downtown Denver. 